\title{
The Translation and Dissemination of the Western Psychology from the Early Republic of China to May $4^{\text {th }}$ Movement
}

\author{
Yanfeng $\mathrm{Hu}$ \\ Foreign Language Department, Dezhou University \\ Dezhou 235023, Shandong, China \\ E-mail: huyanfeng7548@sina.com
}

\begin{abstract}
The period from the early Republic of China to May $4^{\text {th }}$ Movement is the crucial turning stage in the Chinese psychology translation history. During this time, the oversea students ever studying in Japan dominated the translation circle, and meanwhile some professional intellectuals ever studying in America began to join this circle. Therefore, the translation of this time not only maintained the former historical marks, but also began to take on many characteristics appearing after May 4th Movement.
\end{abstract}

Keywords: The oversea students, Republic of China, May $4^{\text {th }}$ Movement, The western psychology, The translation and dissemination

The oversea students were a group of special new intellectuals in the history of Modern China, who played the very important role in the transformation of the Chinese traditional sciences and establishment of the new sciences. During this course, history entrusted to the oversea students multiple roles: both the disseminators of the western advanced culture and the founders of the Chinese new sciences, both the distinguished scholars and the successful translators. As the disseminators and translators of the western culture, they occupied an important position in the Chinese translation history in Modern Time. From the early years of Republic of China to May 4th Movement, history witnessed the birth of the Chinese new sciences, and meanwhile this period was also the crucial transitional stage in the Chinese translation history. At this time, the Chinese translation not only maintained the former historical marks, but also began to take on many characteristics appearing after May 4th Movement. As to the situation of the translation of the western psychology, the case was also like this. However, rare researches in this aspect can be found today in China for some reason, therefore, for the sake of clarifying this span of history, this paper tries to comb the dissemination and the translation of the western psychology the oversea students made during this period.

\section{The historical background of the western psychology translated in Modern China}

After Republic of China was founded in 1912, education was regarded as the effective way to rescue the nation. Ministry of Education promulgated a new educational system, Renzi Educational System on Sept.3, 1912. Law of College Curriculum was issued on Jan.12 next year, and it ruled that psychology was set in the department of philosophy. On February 24, Ministry of Education promulgated Law of Junior Teachers' College Curriculum again, and it ruled that psychology was set the public course for the regular college students in each department. The issue of these educational system and laws were of great importance for the dissemination of western psychology in China. First of all, it meant that psychology was accepted as an independent subject, instead of the auxiliary tool of pedagogy. Secondly, it meant that the dissemination of the western psychology was more widespread. Compared to Qing Dynasty, we can see that the dissemination and translation of the psychology in this period made the greater progress in range and depth. The establishment of subjective position of psychology in the Chinese educational system offered the historical opportunity for the translation, and the oversea students with professional knowledge and proficient foreign language skill turned this dream into reality in the process of western knowledge to China.

\section{Caiyuanpei and the dissemination of the western psychology}

From the year 1907 to 1913, Caiyuanpei went to Germany twice for further education, where he studied Wundt's psychology systematically. As he said himself, he paid much attention to experimental psychology and aesthetics (Cai, 1984, p.327). In his article Evolution Theory of Ethnology, he said (1988,p.455) that he always studied philosophy, but after arriving in Germany, he found its scope was too wide, so he wanted to narrowed his researching range and then 
turned to the experimental psychology. The studying experience in Germany and his preference to the experimental psychology made great influence on his educational value. After returning home, he was appointed Minister of Education. During his term, he paid much attention to the development of psychology and spared no effort to advocate the experimental psychology. Firstly, Caiyuanpei paid attention to the application of psychology in education. Once he pointed out (1984, p.59) that the new education must base on experimental pedagogy, which was the newest science in Europe and America. The experimental psychology had the close relationship with the experimental child psychology. Therefore, Caiyuanpei thought it was very crucial for the educators to analyze and master deeply the law of somatopsychic development of the child. Based on such principles of psychology, Caiyuanpei put forth his five educational policies, that's, militarism, materialism, moral education, world outlook and esthetic education. Secondly, Caiyuanpei paid more attention to the scientific and experimental methodology of psychology. In his opinion, the reason why the European science was most developed was that it based on the experiment, and the new mental science also tended to rely on it (Cai 1985, p.339). Therefore, Caiyuanpei inherited Wundt's psychological researching method. He said that once upon time many subjects were not scientific, for example psychology attached to philosophy before, now became a science when it applied the method of applied physics and physiology (1988,p.171). Owing to his psychological view, Caiyuanpei supported the development of the Chinese psychology positively, for example, with his help the Chinese first psychology laboratory was founded in 1917 in Beijing University, and later he established the psychology institute in Academia Sinica. So Caiyuanpei was considered to be a pioneer in the Chinese psychology history because of his contribution to the dissemination of the western psychology in Modern China.

\section{The dissemination of the western psychology by the oversea students studying in Japan}

The dissemination of the western psychology in Modern China owed to the oversea students studying in Japan first, especially in the aspect of translation, they played an important part from late Qing Dynasty to early Republic of China, among whom Chendaqi was a typical case.

Chendaqi (1886-1983), another name Chenbainian, was born in Haiyan, Zhejiang Province. At the age of 17, he went to Japan for seeking knowledge. Later he entered Tokyo Imperial College majoring in psychology and finally he was awarded bachelor's degree. In 1902, Chendaqi returned home and taught psychology in Beijing Politics \& Law School. Then he was invited to Beijing University in 1914 and held the post of the dean of psychology department. With the help of Caiyuanpei, he established the Chinese first psychology laboratory in the department of philosophy. Though the condition of the laboratory was extremely poor, its foundation was a milestone in the Chinese psychology history, symbolizing the establishment of the psychology position in the Chinese higher education system and indicating the start of the psychological study. Additionally, before this, the Chinese students never heard of psychology laboratory and they felt mysterious about it. Now its appearance aroused their aspiration to knowledge and so some of them were determined to study psychology. The famous psychologist, Panshu, was a typical case. According to his reminiscence, in the year 1917 when he just entered Beijing University, he found that a room in front of the library was always locked, a board on the door with the characters Room for Psychology Instrument and Specimen. Whenever passing by, he always felt mysterious and never knew what was hidden in it. Until the next year, when Mr. Chendaqi initiated a short term course named Psychology Experiment, and offered another room for the students' experiment, he began to choose this course without any reason(Pan, 1930).

Chendaqi's another contribution to the early development of Chinese psychology was translations. He translated and edited Outline of Psychology, which was the Chinese first psychology text book for college students. This book was published by Shangwu Publishing House in Oct. 1918, with 15 chapters and 216 pages, mainly involving the physiological base and mental mechanism about feeling, sensation, conception, memory, imagination, will, thinking and personality. In order to clarify the conception of the term psychology, Chendaqi explained it scientifically on the first page. It read psychology mainly studied mental phenomenon, including its structure, its activity and its growth procedure. In the following, he pointed out the difference between psychology and philosophy. Finally, he introduced its researching method. He said induction was dominated in studying psychology, which was a bit different from other subjects. But he thought introspective method, observation method and experimental method should be regarded as auxiliary methods(Chen, 1918, p.4. 5. 9. 10.). After publishing, this book became popular with the circle of psychology for its popular language and its rich and new content. From 1918 to 1929, Outline of Psychology was republished more than 14 times. Chendaqi's other translations are as follows: Child Psychology, Outline of Forensic Psychology etc.

\section{The oversea students studying in America made a figure in the dissemination of the western psychology}

In the $20^{\text {th }}$ century large quantities of Chinese students who were sent to study in America began with the year 1908, which was called Study Abroad Using Geng Zi Reparation in the history. After Eight-Power Allied Forces invaded China, Qing Dynasty was forced to sign Xin Chou Treaty. According to the treaty, the powers grabbed a huge sum of reparation from China, which called Geng Zi Reparation. In May, 1908, U. S. Congress passed a bill officially, which decided to return the redundant reparation for aiding financially the Chinese excellent youths to go to America for higher education. Two months later Qing Dynasty set the office in Beijing, in charge of choosing the candidates. From 
the year 1909 till 1911, three examinations were held and 180 students were chosen. In 1911, Tsinghua School was founded, and this was the preparatory school for study abroad. Therefore, the high tide of study abroad in the early Republic of China appeared, among which many students majored in psychology. But only several oversea students returned home before May $4^{\text {th }}$ Movement, they were WangChangping, doctor of Michigan University, Chenheqin, master of Columbia University, Lingbing, doctor of Clark University, and Liaoshicheng, doctor of Columbia University etc. Though the returned oversea students were in small scale, they became the leaders in the field of dissemination and translation of western psychology because of their higher professional qualities. For example, Chenheqin, on return, spared no effort to introduce the western child psychology knowledge and its researching method, which laid the foundation for the establishment of the Chinese own child psychology, while Liaoshicheng brought about a new situation for the development of the Chinese educational psychology owing to his excellent work. After May $4^{\text {th }}$ Movement, large scale of oversea students majoring in psychology began to return home successively, and they gradually became the leading force in this field.

\section{Publishing of the western psychology books in this period}

From early Republic of China till May $4^{\text {th }}$ Movement, there were 15 kinds of foreign psychology books translated into Chinese by oversea students in total, as follows:

Lingqiao: Psychology of Mirage World (Shangwu Publishing House, 1911), Huirenlun, Pengqingpeng: Common Child Psychology (Jilin Library,1912), Pengshifang: The Chinese psychology Textbook(Chung Hwa Book Co. 1912), Jiangweiqiao: Psychology Lecture Notes (Shangwu Publishing House, 1912), Zhouweicheng: Child Psychology (Beijing Pointer Publishing House,1914), Zhangyucong, Shenchengqing: Psychology New Textbook for Normal School (Shangwu Publishing House, 1915), Gugongyi: New Psychology (Chung Hwa Book Co. 1915), Zhangzihe: Extensive Psychology(Shangwu Publishing House, 1915), Zhuguang, Yangbaoheng: Lecture Notes of Practical Child Psychology (Chung Hwa Book Co. 1915), Fanbingqing: Essentials of Psychology for Normal School (1915), Chenshiwu: Practical Methods for correcting Eccentricity (Shanghai Youzheng Book Co. 1916), Yuji: Essentials of Psychology(Shangwu Publishing House, 1917), Caiyuanpei: Pandect of Parapsychology(Shangwu Publishing House, 1917), Dushiye: Revolution Psychology (1918), Liurenhang: Methods for Increasing Memory (1918).

Through analysis, we can see that these books translated or edited in this period possess the following characteristics:

(1) Most of the translators or the editors were oversea students ever studying in Japan., such as Lingqiao, Pengqingpeng, Zhangyucong, Fanbingqing etc. So the oversea students ever studying in Japan played an important role in the dissemination of the western psychology during this period. (2) The original texts took on diversity. In late Qing Dynasty, the original texts mainly came from Japan, but at this time the number of the original texts from America, Germany, and France increased gradually. Such change reflected that the range of the translators' knowledge and outlook was becoming wider and wider gradually, and meanwhile it symbolized that the subject consciousness of the translators was becoming stronger and stronger when choosing the translating texts. (3) The contents of psychology were becoming richer and richer. In late Qing Dynasty, most of the translated psychology books were related to educational psychology, while in this period people changed their psychology value that it was only attached to pedagogy. The translators now regarded psychology as an independent subject, so they broke the fixed mindset in the process of knowledge-introduction and different kinds of psychology were translated or edited, such as common psychology, child psychology, abnormal psychology, social psychology and educational psychology etc. (4) The creative consciousness of the translators was increasing. Compared with the late Qing Dynasty, a significant change was taking place in translating, that's, the number of the translated books was reducing, while the number of the compiled books was increasing. Among the 15 publications, 12 books were compiled by the writers, covering $80 \%$ of the total. Although these compiled books also based on the foreign psychology and rarely possessed the authors' own understanding, this phenomenon manifested both the creative consciousness and the subject consciousness of the native translators were increasing gradually.

\section{Summary}

To sum up, the dissemination and translation of the western psychology in China during this period took on some delightful changes, but there existed lots of defects on the whole. For example, the proportion of the texts from Japan was still high, and meanwhile the translated or edited books were discrepancies in the quality and lacked systematicity etc. However, with the guarantee of the educational system, some related courses were set in the college. Additionally, some returned professional oversea students also strengthened the force of disseminators. All of this made the dissemination of the western psychology in China went farther.

\section{References}

Cai, yuanpei. (1984). The Complete Works of Caiyuanpei. Shanghai: Chung Hwa Book Co. Volume 3, p.327.

Cai, yuanpei. (1984). The Complete Works of Caiyuanpei. Shanghai: Chung Hwa Book Co. Volume 1, p.59. 
Cai, yuanpei. (1985). The Complete Works of Caiyuanpei. Shanghai: Chung Hwa Book Co. Volume 2, p.339.

Cai, yuanpei. (1988). The Complete Works of Caiyuanpei. Shanghai: Chung Hwa Book Co. Volume 6, p.455.

Cai, yuanpei. (1988). The Complete Works of Caiyuanpei. Shanghai: Chung Hwa Book Co. Volume 5, p.171.

Chen, daqi. (1918). Outline of Psychology. Shanghai: Shangwu Publishing House. P.4-5, P.9-10.

Pan, shu. (1930). The Psychology Department In Native University. Semimonthly of National Central University, Vol. 1, No. 2. 